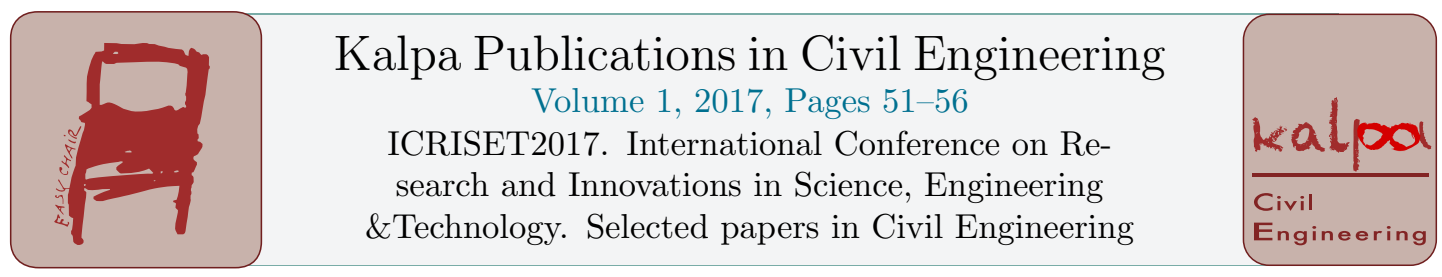

\title{
Study of Dynamic Response of Wall Panel Subjected to Blast Load
}

\author{
Palak Shukla $^{1 *}$, Atul Desai ${ }^{2 \dagger}$ and Chetankumar Modhera ${ }^{2 \dagger}$ \\ ${ }^{1}$ Shri K J Polytechnic, Bharuch \\ ${ }^{2}$ SVNIT, Ichchhanath, Surat, Gujarat, 395007, India \\ palak.shukla80@gmail.com, atuldesai61@gmail.com, cdmodhera@gmail.com
}

\begin{abstract}
Now a days due to increase in the terrorist activities, it becomes necessary to study the response of building when subjected to blast loading. The front wall of the building has direct effect of blast load. In the present study typical reinforced concrete wall panel was consider for dynamic analysis under blast load scenario. The dynamic analysis was carried out using Single Degree of Freedom Blast Effects Design Spreadsheets (SBEDS). The parametric study was carried out to study the effect of compressive strength of concrete, percentage reinforcement, thickness of wall and unsupported length of wall on response of building under blast load scenario. The results were presented in form of displacement time history and pressure impulse diagrams. The results indicate that the displacement of RC wall panel decrease as the increase in the thickness of wall panel, grade of concrete and percentage of reinforcement, but with the increase in unsupported length of RC wall panel, the displacement increases. The mode of failure of RC wall panel under blast load scenario was predicted using pressure impulse diagram. It was observed that as the increase in unsupported length of shear wall, the shear wall was prone to fail in flexural failure mode in impulsive as well as quasi-static region. The results also indicate that as the increase in thickness of wall, percentage reinforcement and compressive strength of concrete, the shear wall was prone to fail in direct shear mode in impulsive region and flexural mode in quasi-static region.
\end{abstract}

Key words: blast load, unsupported length, pressure-impulse diagram, displacement time history

\footnotetext{
* Lecturer, Applied Mechanics

†Professor, Applied Mechanics
} 


\section{Introduction}

Due to considerable increase in terrorist attack, it becomes necessary to study the dynamic behavior of conventionally designed reinforced concrete buildings subjected to blast loading. It becomes important to understand the response of reinforced concrete as a structural material when subjected to large stresses rates through explosive loading (Mutalib, Abedini, Baharom, \& Hao, 2013).Some RC Structural wall panels are designed to function as an efficient bracing system and to offer great potential for both lateral load resistance and drift control (Ioannis, Michel, \& Nicholas, 1990). Numbers of researchers have studied the behavior of various reinforced concrete structural elements subjected to blast loading. Thiagarajan et al. (Thiangarajan, Kadambi, Robert , \& Johnson, 2015) experimentally and numerically studied the response and behavior of high strength concrete and normal strength concrete slabs doubly reinforced with high strength low alloy vanadium reinforcement and conventional steel reinforcing bar subjected to explosive loads. Yao et al. (Yao S. , Zhang, Lu, Chen, \& Wang , 2016) analyzed numerically and experimentally the anti-blast performance and damage characteristic of reinforced concrete slab with different reinforcement ratios and shows that the reinforcement ratio has great influence on the survivability of RC slabs when subjected to blast loading. Yan et al (Yan, Song, \& \& Jiang, 2016) investigate numerically, the damage mechanisms of $\mathrm{RC}$ beam under close in blast loading and found that the tensile stress wave reflected from the free bottom surface of the beam is the major reason of spallation at the bottom. The evolving and meeting up of the two kinds of vertical cracks is the major reason for the main crack propagation, the transversal expansion resulting from Poisson's effect leads to exfoliation of the side cover concrete. The anti blast performance and damage characteristics of reinforced concrete beams with different stirrups ratios were analyzed by Yao et al. (Yao S., Zhang, Lu, \& Wang, 2016). Qu et al (Qu, Li, Kong, \& Zhang, 2016) conducted the numerical studies to study influence of weights and position of explosive charges, locations, widths and depth of initial cracks and longitudinal reinforcement ratio on the dynamic behavior of simply supported RC beam with initial cracks.

\section{Methodology of Present Study}

In the present, study the typical RC Wall panel having $3 \mathrm{~m}$ height, $200 \mathrm{~mm}$ thickness and $0.8 \%$ reinforcement with M25 grade of concrete was considered for blast load analysis. The explosion source is considered as vehicular bomb having $250 \mathrm{~kg}$ of TNT as charge weight and assumed standoff distance $30 \mathrm{~m}$. The dynamic analysis was carried out using the Single Degree of Freedom Blast Effects Design Spreadsheets (SBEDS). The SBEDS workbook is an Excel based tool for design of structural components subjected to dynamic loads using single degree of freedom (SDOF) methodology (U. S. Army Corps of Engineers, 2005). The typical wall was modeled as equivalent spring mass system with non-linear spring. SDOF calculations are performed using a constant velocity numerical integration method.

A numerical parametric study was carried out to investigate the influence of unsupported length (height of wall), thickness of wall, compressive strength of concrete and percentage of reinforcement on response of RC wall subjected to typical blast load scenario. The study include 27 sets of three analysis with $0.8 \%, 1 \%$ and $1.2 \%$ tensile reinforcement and each analysis in a set had same unsupported length, compressive strength of concrete and thickness of wall. Furthermore, explosion sources $250 \mathrm{~kg}$ of TNT at $30 \mathrm{~m}$ standoff distance was remain same for each analysis set.

The result outputs are generated in form of maximum response parameters, displacement time history, applied pressure time history, resistance displacement curve and dynamic shear history. SBEDS plots several P-I curve of the equivalent spring mass system for given component (Engineers, 2008). In the present study the P-I curves were generated considering maximum displacement due to maximum 
calculated ductility ratio for shear-controlled response of wall panel and maximum calculated support rotation for flexure-controlled response of wall panel.

\section{Results and Discussion}

After performing single degree of freedom analysis using SBEDS worksheets, results were generated in form of displacement time history (typical displacement time history as shown in Figure 1 and Figure 2) and pressure impulse diagram. Table 1 indicates the various cases considered for parametric study.

\subsection{Effect of unsupported length of wall panel}

It is observed from Table 1 that as the unsupported length increases the maximum displacement increases for the given blast load scenarios. For example, for $3 \mathrm{~m}$ high $\mathrm{RC}$ wall panel with concrete grade of M30, thickness as $300 \mathrm{~mm}$ and percentage of steel as 1.2 gives displacement of $3.3 \mathrm{~mm}$ whereas $5 \mathrm{~m}$ high wall panel give maximum displacement $13.81 \mathrm{~mm}$. Similar trend was observed for other load combinations as well keeping other parameters same i.e. grade of concrete, thickness and $\%$ of steel. It can be seen from results of pressure impulse diagram as shown in Figure 3 that the RC wall panel with $3 \mathrm{~m}$ unsupported length is prone to fail in shear in impulsive region and flexure mode in quasi static region. When the unsupported length was increased to $5 \mathrm{~m}$ the RC wall panel was prone to fail in flexural mode in impulsive region and shear mode in quasi static region as shown in Figure 5+

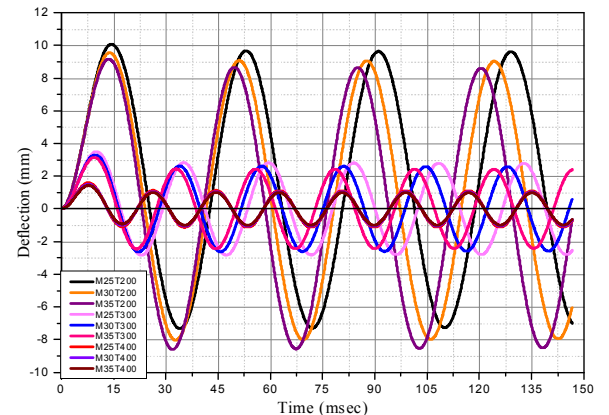

Figure 1 : Displacement time history for $3 \mathrm{~m}$ unsupported length of wall panel and percentage reinforcement $1.2 \%$

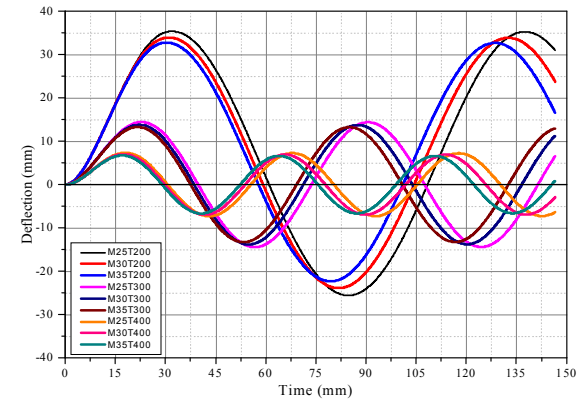

Figure 2: Displacement time history for $5 \mathrm{~m}$ unsupported length of wall panel and percentage reinforcement $1.2 \%$

\subsection{Effect of compressive strength of concrete}

The variation in the strength of concrete for parametric study is indicated in Table 1. It was observed that as the compressive strength of concrete increases the maximum displacement and maximum impulse decrease for given blast load scenario. For example, for $400 \mathrm{~mm}$ thick wall panel having $4 \mathrm{~m}$ unsupported length with M25 grade of concrete, reinforced with $1.2 \%$ steel gives maximum displacement $3.93 \mathrm{~mm}$ where as wall panel having M35 grade of concrete keeping other parameter same gives maximum displacement of $3.57 \mathrm{~mm}$. It was observed in various parametric studies that as the compressive strength of concrete increases the impulse on the $\mathrm{RC}$ wall panel decreases. In Figure 4, the maximum impulse for typical RC wall having $3 \mathrm{~m}$ height, $200 \mathrm{~mm}$ thickness with $1.2 \%$ reinforcement ratio was reduced from $59024 \mathrm{kPa}-\mathrm{msec}$ for M25 grade of concrete to $57464 \mathrm{kPa}-\mathrm{msec}$ for M35 grade of concrete. 


\subsection{Effect of percentage reinforcement}

It is observed from Table 1 that as the percentage of reinforcement increases the maximum displacement decreases for given blast load scenario. For example, $300 \mathrm{~mm}$ thick wall having unsupported length $4 \mathrm{~m}$ with M35 grade of concrete and 0.8 percentage of reinforcement gives maximum displacement of $7.77 \mathrm{~mm}$ which is reduced to maximum displacement $7.41 \mathrm{~mm}$ for the case of wall panel with 1.2 percentage of reinforcement keeping other parameters same.

\begin{tabular}{|c|c|c|c|c|c|c|}
\hline \multirow{2}{*}{$\begin{array}{l}\text { Wall } \\
\text { ID }\end{array}$} & \multirow{2}{*}{$\begin{array}{c}\text { Unsupported } \\
\text { length of RC } \\
\text { wall (m) }\end{array}$} & \multirow{2}{*}{$\begin{array}{l}\text { Compressiv } \\
\text { e strength of } \\
\text { concrete } \\
\left(\mathrm{N} / \mathrm{mm}^{2}\right)\end{array}$} & \multirow{2}{*}{$\begin{array}{c}\text { Thickness } \\
\text { of RC } \\
\text { wall }(\mathrm{mm})\end{array}$} & \multicolumn{3}{|c|}{ Maximum Displacement (mm) } \\
\hline & & & & $0.80 \%$ & $1 \%$ & $1.20 \%$ \\
\hline 1 & 3 & 25 & 200 & 10.66 & 10.24 & 10.07 \\
\hline 2 & 3 & 25 & 300 & 3.7 & 3.59 & 3.495 \\
\hline 3 & 3 & 25 & 400 & 1.71 & 1.65 & 1.59 \\
\hline 4 & 3 & 30 & 200 & 10.1 & 9.71 & 9.56 \\
\hline 5 & 3 & 30 & 300 & 3.49 & 3.39 & 3.3 \\
\hline 6 & 3 & 30 & 400 & 1.61 & 1.55 & 1.51 \\
\hline 7 & 3 & 35 & 200 & 9.65 & 9.26 & 9.17 \\
\hline 8 & 3 & 35 & 300 & 3.32 & 3.22 & 3.14 \\
\hline 9 & 3 & 35 & 400 & 1.53 & 1.48 & 1.43 \\
\hline 10 & 4 & 25 & 200 & 23.27 & 21.77 & 21.38 \\
\hline 11 & 4 & 25 & 300 & 8.55 & 8.33 & 8.13 \\
\hline 12 & 4 & 25 & 400 & 4.18 & 4.05 & 3.93 \\
\hline 13 & 4 & 30 & 200 & 22.37 & 20.81 & 20.41 \\
\hline 14 & 4 & 30 & 300 & 8.13 & 7.92 & 7.74 \\
\hline 15 & 4 & 30 & 400 & 3.96 & 3.84 & 3.73 \\
\hline 16 & 4 & 35 & 200 & 21.64 & 20.03 & 19.6 \\
\hline 17 & 4 & 35 & 300 & 7.77 & 7.56 & 7.41 \\
\hline 18 & 4 & 35 & 400 & 3.76 & 3.67 & 3.57 \\
\hline 19 & 5 & 25 & 200 & 38.75 & 36.18 & 35.39 \\
\hline 20 & 5 & 25 & 300 & 15.09 & 14.73 & 14.23 \\
\hline 21 & 5 & 25 & 400 & 7.75 & 7.53 & 7.33 \\
\hline 22 & 5 & 30 & 200 & 37.46 & 34.79 & 33.95 \\
\hline 23 & 5 & 30 & 300 & 14.42 & 14.09 & 13.81 \\
\hline 24 & 5 & 30 & 400 & 7.38 & 7.18 & 7 \\
\hline 25 & 5 & 35 & 200 & 36.42 & 33.65 & 32.78 \\
\hline 26 & 5 & 35 & 300 & 13.87 & 13.56 & 13.3 \\
\hline 27 & 5 & 35 & 400 & 7.08 & 6.89 & 6.72 \\
\hline
\end{tabular}

Table 1 : Parametric analysis and maximum displacement 
Similar trend is observed for other load combinations as well keeping other parameters same i.e. grade of concrete, thickness and unsupported length. It can be observed from Figure 3 and Figure 4 that for typical $3 \mathrm{~m}$ unsupported length of RC wall with M25 grade of concrete and 200mm thickness of wall, the impulse were reduced from $59037 \mathrm{kPa}-\mathrm{msec}$ for $0.8 \%$ of reinforcement to $59024 \mathrm{kPa}-$ msec for $1.2 \%$ of reinforcement

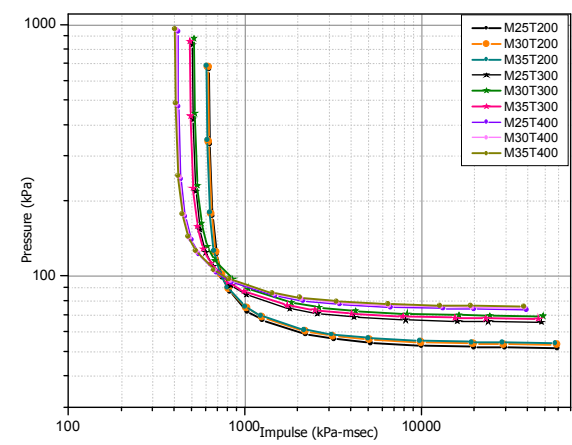

Figure 1 : Pressure impulse diagram of wall panel $3 \mathrm{~m}$ high and 1.2 percentage reinforcement

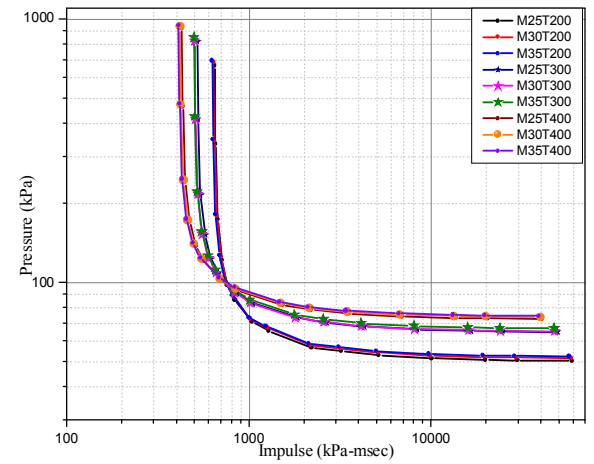

Figure 2 Pressure impulse diagram of wall panel $3 \mathrm{~m}$ high and 0.8 percentage reinforcement

\subsection{Effect of thickness of wall panel}

From the parametric study carried out for the various load cases and variation in the properties as shown in the Table 1, it was observed that as the thickness of wall increases the maximum displacement and maximum impulse decrease for the given blast load scenarios. For example, for concrete grade of M35, with wall thickness as $300 \mathrm{~mm}$ and percentage of steel as 1, the $4 \mathrm{~m}$ high panel gives displacement of $7.56 \mathrm{~mm}$ whereas $400 \mathrm{~mm}$ thick wall panel gives maximum displacement 3.67 $\mathrm{mm}$. Similar trend is observed for other load combinations as well keeping other parameters same i.e. grade of concrete, unsupported length and \% of steel. Figure 6 indicates the pressure impulse diagram of $4 \mathrm{~m}$ high $\mathrm{RC}$ wall panel with 1.2 percentage of reinforcement with different thickness of wall 200 $\mathrm{mm}, 300 \mathrm{~mm}$ and $400 \mathrm{~mm}$. It can be observed that as the thickness increase the flexure failure curve move below direct shear curve in quasi-static region. So the $\mathrm{RC}$ wall panel prone to fail in flexural mode in quasi-static region and prone to fail in direct shear mode in impulsive region.

\section{Conclusion}

In the present study the typical reinforced concrete wall panel was considered for blast load analysis. The RC wall panel was subjected to blast load generated due to explosion of $250 \mathrm{~kg}$ of TNT charge weight at $30 \mathrm{~m}$ standoff distance. The dynamic analysis was carried out using the SBEDS. The parametric study was carried out to study the effect of unsupported length of wall panel, concrete compressive strength, percentage of reinforcement and thickness of wall panel on response of wall panel to the applied blast load. The response of RC wall panels in form of displacement time history and pressure impulse diagram for various cases were generated. The following conclusions were drawn:

1. The results of displacement time history indicated that diplacement increase as the increase in unsupported length of RC wall panel.

2. It is interesting to note that the increase in the strength of concrete ,thickness of RC wall panel, percentage of reinforcement result in considerable reduction in the displacement. . 
3. Pressure impulse diagrams indicate the $\mathrm{RC}$ wall panel having smaller unsupported length prone to fail in shear failure mode in impulsive region and tend to fail in flexural failure mode in quasi static region, while higher unsupported length of $\mathrm{RC}$ wall panel results in flexural failure mode in impulsive and quasi staic region..

4. It can be seen from pressure impulse diagram that increase in grade of concrete, percentage of reinforcement contribute the shear and bending capacity of $\mathrm{RC}$ wall panel

5. It can be seen from results that as the thickness of $\mathrm{RC}$ wall panel increases the $\mathrm{RC}$ wall panel tend to fail in direct shear mode in impulsive region and tend to fail in flexural mode in quasi static retion.

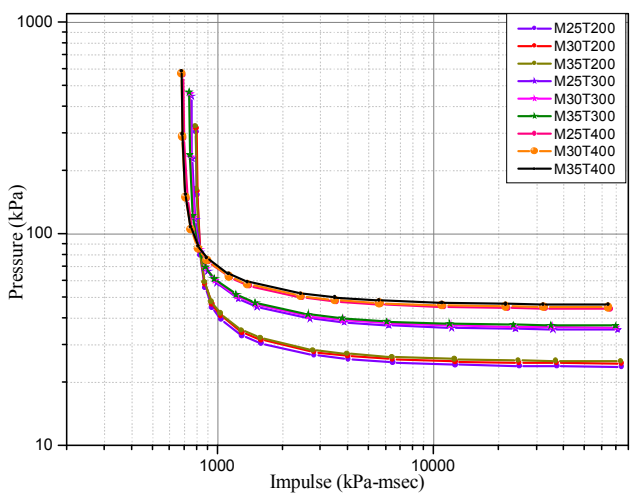

Figure 5: Pressure impulse diagram of wall panel $5 \mathrm{~m}$ high and 1.2 percentage reinforcement

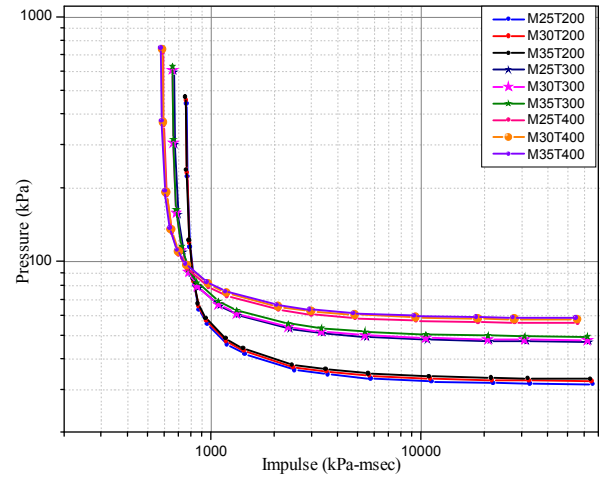

Figure 6: Pressure impulse diagram of wall panel $4 \mathrm{~m}$ high and 0.8 percentage reinforcement

\section{References}

Engineers, U. S. (2008). PDC-TR-06-02 - Users guide for the single degree of freedom blast effects design spread sheets (SBEDS). Protective Design Center.

Ioannis , D., Michel, D., \& Nicholas, N. (1990). Behavior of reinforced concrete structrual walls: strength, deformation characteristic and Failure mechanism. ACI Structural Journal, 23-31.

Mutalib, A. A., Abedini, M., Baharom, S., \& Hao, H. (2013). Derivation of empirical formulae to predict pressure and impulse asymptotes for P-I diagrams of one way RC panels". International journal of civil,, Vol. 7,No 8,pp.585-588.

Qu, Y., Li, X., Kong, X., \& Zhang, W. \&. (2016). Numerical simulation on dynamic behavior of reifnorced concrete beam with initial cracks subjected to air blast loading. Engineering Structures, Volume 128, 96-110.

Thiangarajan, G., Kadambi, A., Robert, S., \& Johnson, C. (2015). Experimental and finite element analysis of doubly reinforced concrete slabs subjected to blast load. International Journal of Impact Engineering, Volumn 75, 162-173.

U. S. Army Corps of Engineers. (2005). PDC-TR-06-01 - Methodology manual for the single degree of freedom blast effects desing spread sheets (SBEDS). Protective Design Center.

Yan, B. L., Song, D., \& \& Jiang, Z. (2016). Numerical study on damage mechanicsm of RC beams under close in blast loading. Engineering Failure Analysis, Volume 51, 9-19.

Yao, S., Zhang, D., Lu , F., Chen , X., \& Wang, W. (2016). Experimental and numerical study on the dynamic response of RC slabs under blast loading. Engineering Failure Analysis, Volume 66, 120-129.

Yao, S., Zhang, D., Lu, F., \& Wang, W. \&. (2016). Damage features and dynamic response of RC beams under blast. Engineering Failure Analysis, Volume 62, 103-111. 